\title{
Implementation of energy service contracts in Russia
}

\author{
Elizaveta Markovskaya ${ }^{1, *}$, Sergey Ryabichenko $^{2}$, Elena Znamenskaya $^{3}$ and Galina \\ Dyakova $^{4}$
}

${ }^{1}$ National Research University Higher School of Economics, 190121, Soyuza Pechatnikov, 16, SaintPetersburg, Russia

${ }^{2}$ Moscow Region State University, 105005, Radio str, 10A, Moscow, Russia

${ }^{3}$ Moscow State University of Civil Engineering, 129337, 26, Yaroslavskoe Shosse, Moscow, Russia

${ }^{4}$ Russian New University (ROSNOU), 105005, Radio str., 22, Moscow, Russia

\begin{abstract}
The article discusses the features of energy service contracts as one of the types of state-business interaction in the form of a public-private partnership. The purpose of the article is to analyze the main problems accompanying the implementation of energy service contracts on the basis of a case analysis and to develop recommendations for those who are at the stage of concluding such agreements. The following causes of problems between the parties to the energy service contracts are highlighted: methodological, organizational and financial. The following recommendations are developed based on the experience of participation in forensic examinations: 1) careful study of the methodology for calculating savings using energy audit; 2) the method of calculating the economic effect should be an integral part of the energy service contract; 3) careful management of documents in order to be able to begin to resolve the conflict in the pretrial order according to the Civil Code; 4) the contractor must make sure that there are economic benefits based on detailed calculations of indicators such as payback period, net present value of the project, internal rate of return, which it is mandatory to compare with the cost of financial resources used in the project.
\end{abstract}

\section{Introduction}

Energy service contracts are a form of state-business interaction in the form of a publicprivate partnership. The purpose of such contracts is to achieve savings in the use of resources (electricity). Savings are achieved through the implementation of certain measures to achieve energy efficiency. As a rule, such events are associated with the replacement of obsolete equipment with another, more modern. The contractors for energy service contracts are private companies that implement such projects at their own expense, hoping to receive a reward, which is calculated as a certain percentage of the savings achieved. The customer of such projects are the Administrations of the subjects of the Federation, city authorities, municipalities. The practice of implementing energy service

\footnotetext{
* Corresponding author: markovskaya@yandex.ru
} 
contracts is still very young. Nevertheless, such projects arouse great interest on the part of government officials. Therefore, it seems to us relevant to analyze the existing legal framework on the basis of which energy service contracts are implemented, based on our experience of participating in specialized forensic expertise, develop a basic list of problems and their causes and develop recommendations for overcoming controversial and conflict situations that may arise between the parties to such agreements.

The authors studied data on the energy service contracts signed since 2006, and published in the Unified Information System in the sphere of purchases, the regions which are the leaders in the quantity of the signed energy service contracts (Figure 1), and the volume of investment (Figure 2) were revealed.

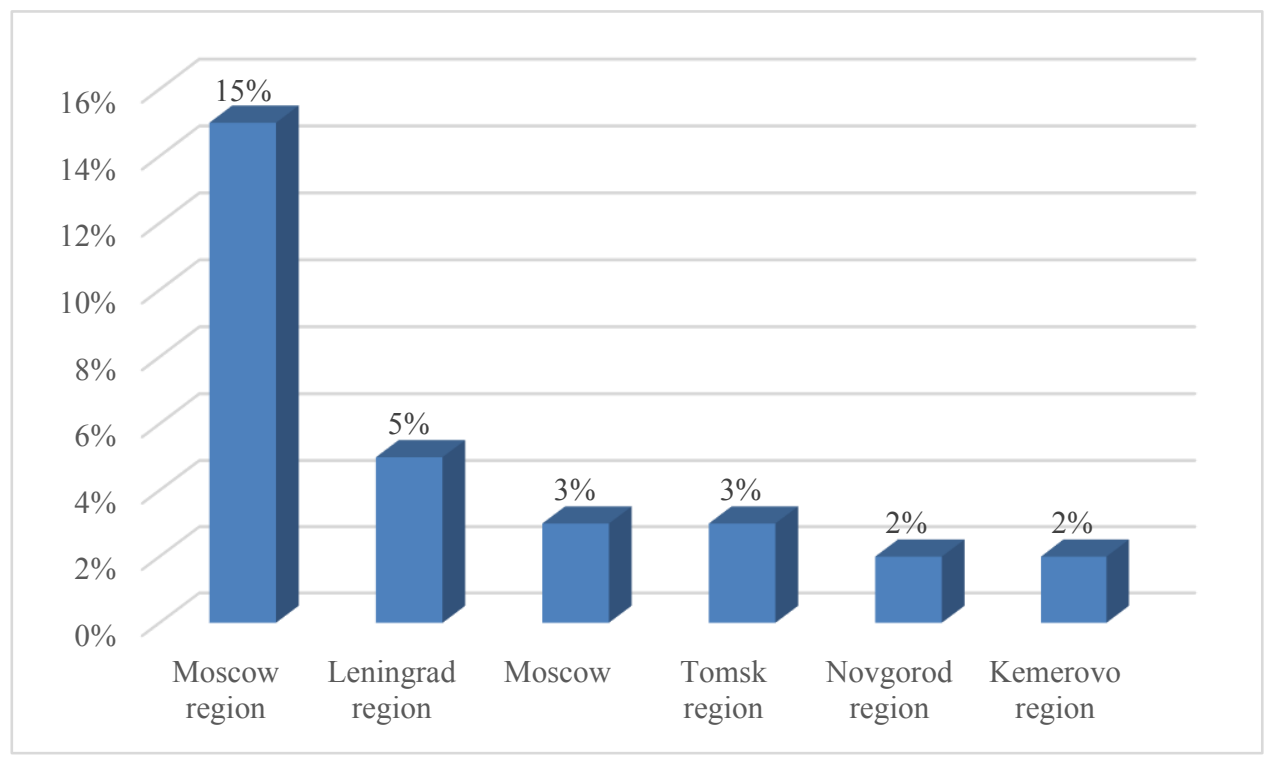

Fig. 1. The quantity of the contracts signed in the leading regions in 2016.

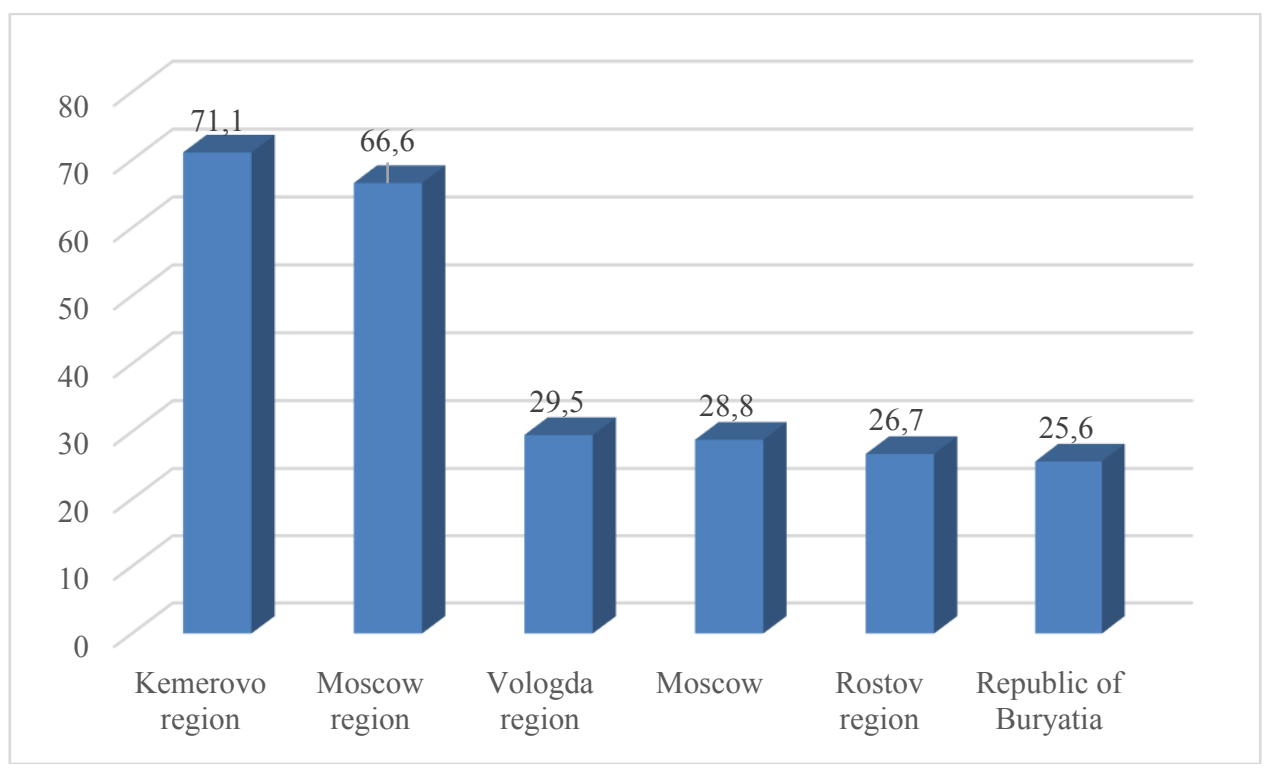

Fig. 2. The volume of investment (million roubles), made in the leading regions in 2016. 
Besides, the distribution of energy service contracts according to the types of facilities (Figures 3, 4) was studied.

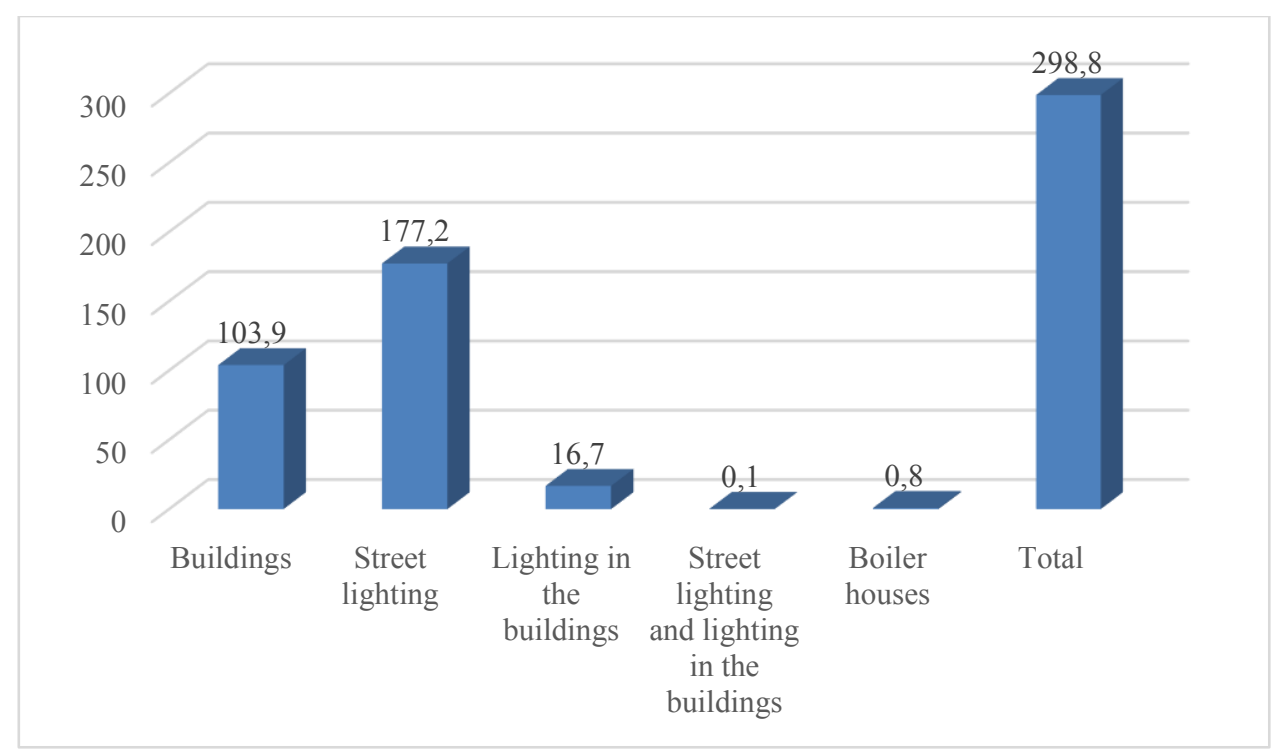

Fig. 3 Cost of service contracts according to the types of facilities (mln. roubles).

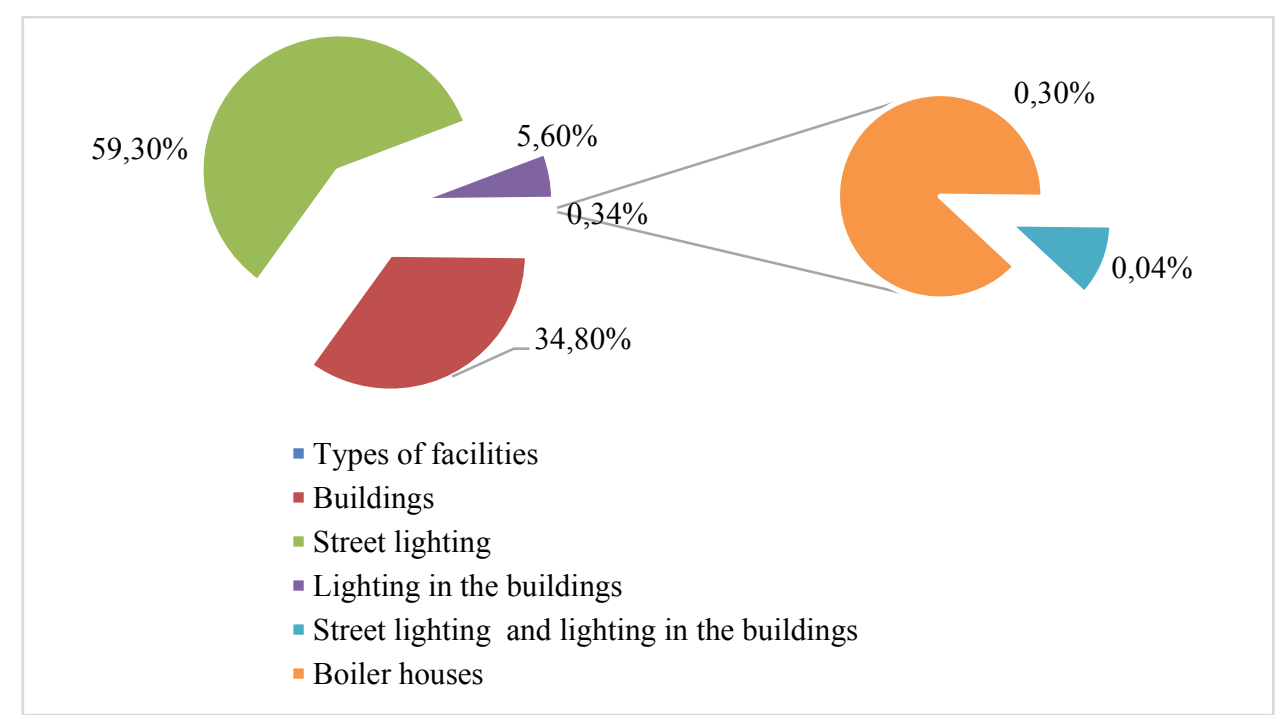

Fig. 4. Distribution of energy service contracts according to the types of facilities.

Such facilities of the social sphere as schools $(16 \%)$ and hospitals of $13 \%$ dominate among the customers of the energy services. Besides, one of contracts is directed to energy saving and to the increase in the energy efficiency of the use of electrical energy for lighting of common areas of 25 apartment buildings in Moscow. About a half of all the contracts are directed to the modernization of street lighting (45\%). 


\section{Methods and Regulation}

This research uses various general scentific methods: logical and graphical methods, the method of synthesis and the system approach, which allowed to understand the existing contradictions in the law and to state the formulation of existing and prognostic problems. The logical method of cognition of the domain allowed assessing the possible prospects for the development of the market for energy services and identifying the most appropriate solutions to problems.

The material of the research is based on the information from the official data of the RAESCO and regulatory and legal documents regulating the activities of energy service companies. The main normative and legal document that determines the principles for the implementation of the energy service contract is the Federal Law No. 261-FZ "On Energy Saving...".

Then the Energy Service Contract (ESC) is referred by the Law on the Contract System to the category of agreements with features. The objectives of such a document are energy saving and measures to improve the use of energy resources (part 1 of article 10844 -FZ) [1]. Its subject is activities to increase the efficiency of consumption. The law gives the customer the right to enter into ESCs, this is further emphasized in the letter of the Ministry of Economic Development dated 09.09.2015 No. D28i-2618 [2]. Moreover, since 2010, state and municipal institutions are obliged to minimize the volume of consumption of water, fuel, natural gas, and thermal energy for five years (Article 24 No. 261-FZ) [3]. Since 2011, the requirements have spread to all state (municipal) institutions: state, budget, autonomous (confirmed by the letter of the Ministry of Finance dated 30.12.2010 No. 0203-06 / 5448) [4]. Customers can conclude an energy service contract based on the results of tenders, electronic auctions and quotation requests (Article 108 44-FZ) [5]. Based on Part 2 of Art. 108 it is concluded separately from contracts: in the field of activity of subjects of natural monopolies; for the provision of services for water supply, drainage, heat supply, gas supply; to connect to engineering networks at regulated prices; on the supply of electricity, fuel oil, coal, fuel in order to generate energy. At the same time, the terms of the energy service contract may be included in contracts for the sale, delivery, transfer of energy resources (Art. 20 261-FZ). The main volume of activity falls on energy service contracts in the public sector, in the housing sector and in industry [6].

In a number of cases, PSC establishes a contractual relationship for a long period. In a short time, there is less chance of real savings. The customer needs to anticipate the result, ensure the conditions for fulfilling the obligations assumed by the parties, and create opportunities for equipment recoupment. Sometimes these periods exceed 10 years. With such long-term plans, it is more difficult to foresee the risks of costs and accurately calculate the effectiveness. The customer needs to clearly represent the amount of resources that he has without energy saving. Based on this, you need to be able to calculate the planned volume of consumption. The customer will need to lay and consider the possibility of unforeseen factors in the form of changes in weather conditions or a sharp increase in the number of consumers. He will need to think about ownership of the equipment. The savings can be redistributed to increase the salary of employees (letter of the Ministry of Finance dated December 30, 2010 No. 02-03-06 / 5448) [7].

The energy service contract is concluded at a price that is defined as a percentage of savings on the cost of energy supply in accordance with the proposal of the winner of the purchase (part 13 of article 108 44-FZ): in relation to the maximum percentage specified in the documentation on the basis of paragraph 1 part 3 article 108; on the basis of the percentage of economy payable to the executor with the minimum size on the basis of clause 2 of part 3 of art. 108; in the form of the minimum amount of cost savings of the customer, the maximum percentage of which can be paid to the winner in accordance with 
paragraph 3 of part 3 of article. 108. At the conclusion, it is indicated the savings in physical terms of the customer's expenses for the supply of energy resources for each type of such resources. Indicators are calculated in accordance with paragraphs 1, 2, 3 hours. 3 Art. 108. The payment of the energy service contract is made on the basis of the amount of energy savings of the customer provided for in it and the percentage of such savings. Savings are determined by the prices of existing energy for the period of execution of the contractual relationship [8].

The current legislation determines who establishes the requirements for the conditions of an energy service contract. Such powers have allocated government bodies. Government Decree dated 08.18.2010 No. 636 installed two applications that contain the Requirements for the terms of the contract $[9,10]$.

\section{Results}

Requirements for some ESC conditions are determined by the need for: availability of a list of energy saving measures with a technical description of each event and deadlines; the lack of compensation to participants in the costs of the preparatory work for filing their application; determine the amount of energy savings for the contractor; the existence of a provision under the terms of which the contractor's savings obligation was considered fulfilled when the amount of savings that was enshrined in the contractual document was reached or exceeded; taking into account factors that affect the size of savings and the performance of contractual relations, up to a change in the area and volume of premises; designation of the mechanism of distribution between the parties to the contract of additional savings of the energy resource specifying the initial and final deadlines for achieving the amount of savings provided for in the contract.

Our experience of participation in legal expertise related to the implementation of energy service contracts shows that the main problems and disputes between the parties to such contracts may arise at the stage of deciding on the payment of funds, which are defined in the form of savings that the contractor achieves as a result of the implementation of measures defined data contract. Activities that are specified in such energy service contracts, as a rule, are aimed at achieving energy efficiency, that is, saving on the use of resources (in this case, in the situation with energy service contracts, it is about saving electricity), which can be expressed in physical and monetary terms. The experience of participating in specialized forensic examinations allows us to conclude that the following causes of the problems encountered by the parties in the process of implementing energy service contracts can be highlighted:

-organizational

They are connected with the fact that the contractor for the energy service contact practically cannot influence the Customer's management processes and completely becomes a hostage of the strategy pursued by the Customer / And meanwhile, a conflict of interest may arise among different stakeholders within the Administration from the main parties to the contract).

- financial

The contractor performs the work at his own expense at his own risk and risk, counting on receiving economic benefits in the future from achieving savings. We are practically dealing with a full-fledged investment project, which should provide the Contractor, in the person of which, as a rule, private companies act, a tangible, tangible economic effect.

Often, the Contractor performs work, purchases the necessary equipment, using credit resources, which obviously increases the cost of the investment project for the Contractor.

-methodical 
The method by which savings are calculated should be initially clear and transparent so that at the stage of the payment of remuneration to the Contractor, there is no conflict.

The effectiveness of the application and use of energy service contracts is confirmed throughout the world. Russia was no exception. But there some problems, concerning the implementation of energy service contracts in Russia.

The implementation of large-scale projects with a high level of lot prices and, accordingly, a high level of savings is beyond the power of small businesses. At the same time, it is the small business that must provide the main market for energy services, since the "true" energy service, in which the mechanism for implementing energy-saving measures with an "extended" effect is laid down, to large players, cannot be interesting, especially given the current economic conditions management: taxes, salaries, interest on the loan. The monthly or quarterly profit received during the implementation of energy service contracts is postponed and stretched for years.

Without government support, energy service contracts are becoming less attractive with each passing month.

\section{Discussion}

The main recommendations that can be made to the parties to the energy service contract during the contract negotiation phase can be summarized as follows:

1. At the stage of discussing the basic parameters of the contract, when it comes to the method of calculating savings, it is advisable to resort to an energy audit in order for the energy auditor, first, to confirm all the main parameters that will be included in the calculation (usually, we can talk about parameters which are taken as basic and are the main base for comparison).

2. At the stage of development of the calculation methodology, you should make sure that all parties to the energy service contract agree with this methodology. It makes sense to sign this methodology on the part of all participants in the energy service contract, to make it part of this contract, having been issued as an application.

3. Due to the fact that court disputes regarding disagreement with the calculation of savings are very difficult to resolve, it makes sense if any parties disagree with the calculations, immediately resort to the pre-trial procedure for resolving disputes (filing an unilateral transfer statement, as well as a claim). At this stage, it is also advisable to conduct an energy audit procedure in order to begin, before the judicial procedure, to form an evidence base to strengthen its position in court (if you have to resort to this method of resolving a conflict situation).

4. Since the Russian practice of concluding energy service contracts shows that while such a format is not always beneficial for the Contractor, the economic efficiency of such projects should be especially carefully evaluated, calculating the payback period, the net present value of such a project and the rate of return comparing it with the cost used in the project finance resources.

\section{Conclusion}

Energy service contracts are a promising direction for the development of state-business interaction in the form of a public-private partnership. The effective application of such contracts from the Contractor will require preliminary work. It is advisable for the contractor to make sure that there is an economic effect from the implementation of such a contract. It is desirable for the contact executor to conduct an energy audit before entering into a contract, the results of which should be presented to the customer. The method of 
calculating savings, on the basis of which it is planned to calculate the remuneration of the Contractor, it is advisable to include in the contract as an integral part of it so that in the process there would be no controversial situations that are rather difficult to resolve in court.

\section{References}

1. H. Perlwitz, S. Cypra, D. Möst, O. Rentz, BWK: das Energie-Fachmagazin 57(6), 6-9 (2005)

2. C. Jiang, C. Ji, J. Chen, IOP Conference Series Earth and Environmental Science 170(4), 042041 (2018)

3. V. Pukhkal, A. Mottaeva, Magazine of civil engineering 81(5), 202-211 (2018)

4. I. Potekhin, V. Mischenko, A. Mottaeva, A. Zheltenkov, E3S Web of Conference 33, 03020

5. A. Mottaeva, B. Melovic, MATEC Web of Conference 193, 00001 (2018)

6. Won-Jun Park, Hye-Mi Kim, Sustainability 10(4), 1089 (2018)

7. E. Vasilyeva, MATEC Web of Conferences 193, 01025 (2018)

8. E. Vasilyeva, IOP Conference Series Earth and Environmental Science 90(1), 012216 (2017)

9. E.Ganebnykh, A. Mottaeva, T. Larinina, E.Petrova, MATEC Web of Conferences 170, 01044 (2018) doi.org/10.1051/matecconf/201817001044

10. S. Andreev, V. Zaginaylov, A. Matveev, MATEC Web of Conferences 245(3B), 06014 (2018) 